\title{
The social representation of smoking cannabis and driving: comparison between occasional and regular cannabis using drivers
}

\begin{abstract}
In France the consumption of cannabis is one of the highest in Europe and when driving, it multiplies the risk of accidents. In this original study, cannabis users were interviewed in order to show the social representation of smoking cannabis and driving. The comparison focused on occasional $(\mathrm{N}=19)$ vs regular $(\mathrm{N}=46)$ users, all of them drivers. The results confirm the impact of practices on social representations and risk awareness that differs between the two groups.
\end{abstract}

Keywords: driving, occasional vs regular cannabis users, social representations, risk, public health, smoking, tetrahydrocannabinol, alcohol, drugs, road safety, accidents, drinking, speeding
Volume 6 Issue I - 2017

\section{Sandrine Gaymard, Sandy Lucet}

Department of Psychology, University of Angers, Laboratoire de Psychologie des Pays de la Loire (LPPL), France

Correspondence: Sandrine Gaymard, Department of Psychology, University of Angers, Laboratoire de Psychologie des Pays de la Loire (LPPL), France, Tel +33 24I 226 394, Fax +3324I 226 395, Email Sandrine.gaymard@univ-angers.fr

Received: May 12, 2017 | Published: June 13,2017

\section{Problem}

Road safety is a public health issue with more than 1.2 million deaths on the roads every year in the world, 50 million injured and disabled due to road accidents; moreover road accidents are the leading cause of death among young people between the ages of 15 and 19. In France, if the first two causes of accidents identified are drinking and speeding, the fact remains that accidents derive from multiple factors one of which is the association of alcohol/drugs. French law forbids the production, possession, purchase, sale and use of cannabis. Tetrahydrocannabinol (THC) is the most available Cannabinoid and the one most present in the cannabis plant; it possesses psychoactive properties that act on the psyche by modifying the rhythm of the brain. One "joint" which is one of the more iconic ways of consuming cannabis, produces effects equivalent to an alcohol level of between 0.3 and $0.7 \mathrm{~g} / \mathrm{l}$. In 2017 new saliva tests should allow detection within a few minutes if a driver has used drugs (cannabis, cocaine, opiates). Thus if drugged driving is not a new phenomenon, new systems of detection render this phenomenon more visible.

The study of social representations provides information on how an object is appropriated by a group through practices, keeping in mind that one of the functions of social representations is to guide behavior. ${ }^{2}$ The structural approach of social representations ${ }^{3}$ highlights a representation articulated around a central core, which organizes the representation, and a periphery linked to individual practices, while the theory of conditionality ${ }^{4}$ puts the focus on the peripheral system and the conditionality of norms. Several studies in the field of traffic psychology have shown the interest of this field of research to better understand the attitudes and motivations of road users. ${ }^{5-7}$

The aim of this research note is to report on an original topic: the representation of the use of cannabis while driving held by occasional or regular cannabis users who drive. This exploratory study compares the social representation between two groups: occasional and regular users.

The hypotheses put forward are the following:

A. The social representation will differ between the two groups (H1).
According to this hypothesis the central core will differ among occasional users and regular users.

B. The greater the risk-taking in practices, the more users relativize the danger $(\mathrm{H} 2)$.

According to this hypothesis the representation of regular users will show lower risk awareness.

\section{Method}

\section{Tools}

Following exploratory interviews, two tools were built in the frame of this study: a free associations test and a characterization questionnaire. These two tools are complementary and regularly associated in the field of study of social representations. ${ }^{8}$ The free associations test rests on the study of spontaneous representation activated by an inductor, here in the form of a dual inductor. ${ }^{9}$ The instruction was the following: when you hear "cannabis and driving" what do you think of?

The characterization questionnaire was based on the elaboration of 9 items (Table 1) with an idea of ranking by the respondents themselves who had first to choose the 3 items most characteristic of cannabis and driving, these items are coded +1 , and then the 3 least characteristic items which are coded -1 . Those items not chosen are coded " 0 ".

\section{Analyses}

\section{Free associations}

The prototypical method of analysis of social representations ${ }^{10}$ cross-checks the frequency (high or low) and the average rank of appearance (words quoted in the first or in the last ranks) in order to determine the central and peripheral contents of the representation. The central elements are the elements frequently quoted and in the first ranks of appearance. The elements of the first periphery are either those that are frequently quoted but in the last ranks of appearance or those that are rarely quoted but in the first ranks of appearance. The choice of thresholds has been explained elsewhere in detail as 
this choice depends on the number of respondents. ${ }^{11}$ According to this method, the central elements and the first periphery are to be taken into account in the interpretation. The elements of the second periphery do not bear enough weight to enter into the analysis.

Table I Characterization questionnaire (smoking means "smoking cannabis")

Item I: Driving under the influence of psychotropic substances is fatal

Item 2: Smoking while driving is not dangerous

Item 3: Cannabis is among friends, during a party

Item 4: When I smoke and drive, I endanger the lives of others

Item 5: Smoking while driving is a way of being cool

Item 6: Drug testing on the road is a good idea to avoid accidents

Item 7: If I smoke cannabis while driving it is because I am in control of my vehicle

Item 8: Smoking cannabis before driving is risky behavior

Item 9: I do not feel like giving up cannabis smoking even if I drive

\section{Characterization questionnaire}

The data have been recorded according to the usual procedure: 1 $(-1) ; 2(0) ; 3(+1)$. We used Mann Whitney's U test to bring to light the differences in rank between the two groups and we relied on graphic representation for the interpretation.

\section{Population}

The world of cannabis users was approached by means of a user who then broadcast the link of the questionnaire in his personal network and via facebook. After identifying the respondents, a second screening took place in order to be sure that they matched the criteria (occasional vs regular, both drivers). We gathered the answers of 65 respondents: 19 occasional users and 46 regular ones (Table 2).

Table 2 Descriptive statistics for each group

\begin{tabular}{llll}
\hline & $\begin{array}{l}\text { Mean Age } \\
\text { (SD) }\end{array}$ & Median & $\begin{array}{l}\text { Interquartile interval } \\
{[\mathrm{QI} ; \mathrm{Q} 3]}\end{array}$ \\
\hline $\begin{array}{l}\text { Occasional users } \\
\mathrm{N}=19\end{array}$ & $24.84(4.7 \mathrm{I})$ & 25 & {$[20.5 ; 27.5]$} \\
Regular users $\mathrm{N}=46$ & $26.96(7.04)$ & 24.5 & {$[22 ; 30]$}
\end{tabular}

\section{Results}

\section{Free associations test}

For the group of occasional users $(\mathrm{N}=19)$, the discourse production reached 90 words, that is a little less than 5 words per person. For the regular users $(\mathrm{N}=46)$, the discourse production reached 187 words that is a little more than 4 words per person.

The prototypical analysis Tables $3 \& 4$ shows that the social representation differs according to the type of users: occasional vs regular. The central core for occasional users contains the items "dangerous" and "lack of awareness" while the central core for regular users includes the item "law enforcers". It is noteworthy that the central item "dangerous" for the group of occasional users becomes peripheral for the group of regular users. It can also be seen that the peripheral items "accident", "reflex" and "risk" among occasional users are relegated to the second periphery among regular users
Table 3 The social representation of smoking cannabis and driving among occasional users

\begin{tabular}{|c|c|c|c|c|c|c|}
\hline & & & $\begin{array}{l}\text { First } \\
\text { Rank } \\
<2.5\end{array}$ & & & $\begin{array}{l}\text { Last } \\
\text { Rank } \\
>2.5\end{array}$ \\
\hline \multirow{4}{*}{$\begin{array}{l}\text { High } \\
\text { Frequency }\end{array}$} & \multicolumn{2}{|l|}{ Central words } & & \multicolumn{2}{|l|}{ First Periphery } & \\
\hline & Dangerous & $37 \%$ & 1.57 & Accident & $63 \%$ & 2.75 \\
\hline & $\begin{array}{l}\text { Lack of } \\
\text { awareness }\end{array}$ & $26 \%$ & 1.6 & Reflex & $32 \%$ & 3.33 \\
\hline & & & & Risk & $26 \%$ & 3.2 \\
\hline & First Periphery & & & $\begin{array}{l}\text { Second } \\
\text { Periphery }\end{array}$ & & \\
\hline & Illicit & $16 \%$ & 1.67 & Concentration & $11 \%$ & 2.5 \\
\hline \multirow{4}{*}{$\begin{array}{l}\text { Low } \\
\text { Frequency }\end{array}$} & & & & Control & $11 \%$ & 3.5 \\
\hline & & & & Irresponsible & $11 \%$ & 3.5 \\
\hline & & & & Death & $11 \%$ & 2.5 \\
\hline & & & & Stress & $11 \%$ & 4.5 \\
\hline
\end{tabular}

Table 4 The social representation of smoking cannabis and driving among regular users

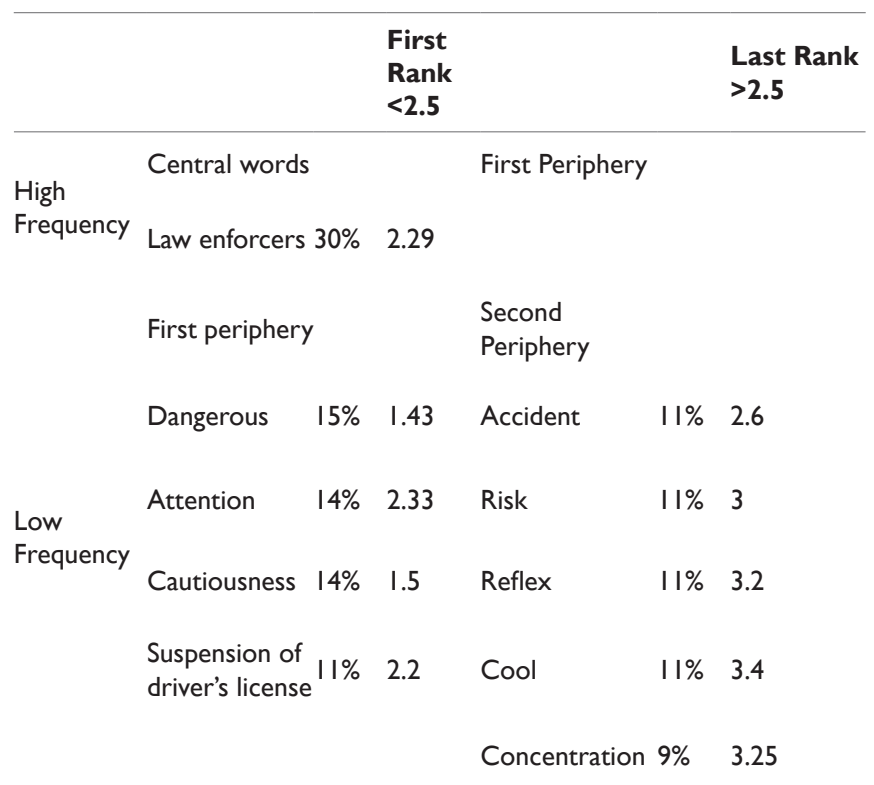

\section{The characterization questionnaire}

The results of the Mann-Whitney test (Table 5) show that the following items are significantly different at threshold .05 between the two groups: item 1 "Driving under the influence of psychotropic substances is fatal"; item 4 "When I smoke and drive, I endanger the lives of others"; item 7 "If I smoke cannabis while driving it is because I am in control of my vehicle"; item 9 "I do not feel like giving up cannabis smoking even if I drive". Figure 1 shows that items 1 and 4 are more characteristic of cannabis and driving for occasional users; conversely items 7 and 9 are more characteristic of cannabis and driving for regular users. It is to be noted that item 6 tends toward significance ("Drug testing on the road is a good idea to avoid accidents"); item chosen as being more characteristic of cannabis and driving for occasional users. 
Table 5 Results with the Mann-Whitney test

\begin{tabular}{|c|c|c|c|}
\hline Items (Table I) & Mann-Whitney U & Z-score & $\begin{array}{l}\text { Significance } \\
\text { p-value }\end{array}$ \\
\hline I. & 262.00 & -2.802 & .005 \\
\hline 2. & 391.00 & -.717 & .473 \\
\hline 3. & 423.50 & -.215 & .830 \\
\hline 4. & 297.00 & -2.201 & .028 \\
\hline 5. & 371.50 & -1.238 & .216 \\
\hline 6. & 319.00 & $-|.90|$ & .057 \\
\hline 7. & 288.50 & -2.279 & .023 \\
\hline 8. & 410.50 & -.436 & .663 \\
\hline 9. & 263.00 & -2.756 & .006 \\
\hline
\end{tabular}

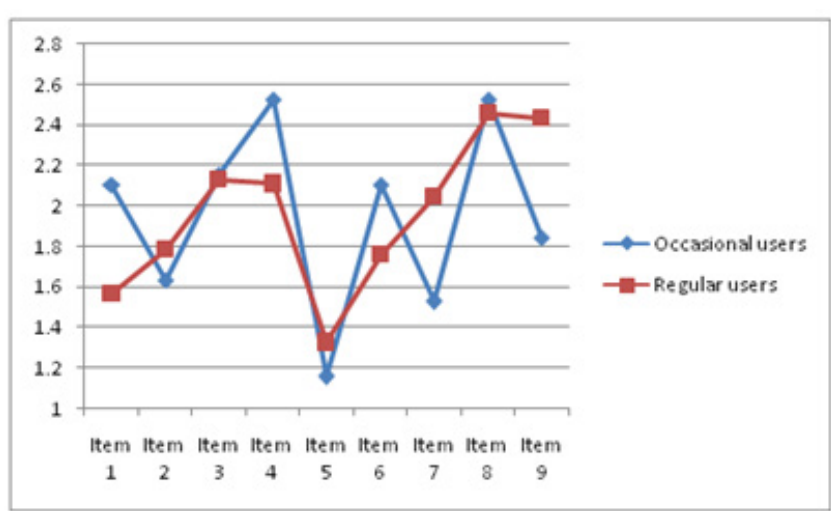

Figure I characterization questionnaire: Means between the least characteristic (I) and the most characteristic (3) of "cannabis and driving" according to occasional or regular users.

\section{Conclusive remarks}

This research note dealt with an original theme, that of the social representation of cannabis while driving according to occasional or regular cannabis users who are drivers too. A mixed method has been used: a free association test and a characterization questionnaire. The hypotheses were based on the link "representations-practices": the social representation will differ in relation to the groups (H1); regular users who take more risks relativize the danger $(\mathrm{H} 2)$. The free associations test, which highlighted the structure of the social representation, confirms that the latter differs according to the group; from a theoretical point of view, the constitution of the core allows us to affirm this. The central core for occasional users is articulated around the dangerous character of the act and a certain moralizing of this (Lack of awareness) reinforced by the term "illicit", which appears in the first periphery. The central core of the regular users is focused on the image of law enforcers, which exacerbates their illicit situation and their fear of law enforcement controls; the item "suspension of driver's license", which appears in the first periphery confirms that they are more worried about these aspects than the risk of an accident. Moreover, their worries evidence a fact: the development of new systems of detection since new saliva tests have been implemented to detect, within a few minutes, whether a driver has used drugs. The structure of the representation also validates hypothesis 2 since the item dangerous, which is central among occasional users thus conferring a systematic character to it (smoking cannabis while driving is dangerous), becomes conditional among regulars users (this depends on circumstances). It is also to be noted that the terms risk, accident and reflex (meaning loss of reflex), which are part of the first periphery of occasional users are no longer relevant to define the representation of regular users, who are however more exposed to risk.

The answers to the characterization questionnaire also go to validate hypothesis 2 . Occasional users appear more aware of the risks linked to the fact of smoking cannabis and driving; effectively items 1 "Driving under the influence of psychotropic substances is fatal" and 4 "When I smoke and drive, I endanger the lives of others" are significantly more characteristic for them than for regular users. Also to be noted are the answers to item 6 "Drug testing on the road is a good idea to avoid accidents" which occasional users judge to be more characteristic reminding us that through their practices, regular users seek rather to avoid these situations by adopting a strategy of careful driving and trying to go unnoticed (see first periphery: "attention", "cautiousness"). On the other hand items 7 "If I smoke cannabis while driving it is because I am in control of my vehicle" and 9 "I do not feel like giving up cannabis smoking even if I drive" are significantly more characteristic for regular users. This supposes that the latter have excessive confidence in their abilities to drive knowing that the use of cannabis has negative effects on driving capacity; ${ }^{12}$ in the same way that the problem of regular use as for alcohol leads to a problem of dependence. ${ }^{13}$

Generally the law and law enforcers stand out in the representation of regular users, which is activated by their daily illicit practices. This aspect associated with justifications such as controlling the vehicle or the conditionality of the danger as well as dependency factors explains that the risk of an accident does not belong to their main preoccupations. Drugged driving campaigns must be developed with precise communication of the impact of drugs on psychomotor skills and of risks run for oneself and others. Reference must clearly be made to the link between consumption of such substances and the risk of serious or fatal road accidents. In this study it can be clearly seen that the risk is perceived as being secondary among regular users; the danger is thus ignored. False beliefs persist, such as the idea that it is less dangerous than alcohol or that one can always control one's vehicle. Driving under the influence of cannabis is a preoccupying problem and fear of the law or controls is at odds with the road safety slogan: "all responsible".

\section{Acknowledgements}

None.

\section{Conflict of interest}

Author declares that there is no conflict of interest.

\section{References}

1. Global status report on road safety. World Health Organization. Geneva: WHO Press; 2015.

2. Abric JC. Pratiques sociales et représentations. Presses Universitaires de France, Paris; 1994.

3. Abric JC. Jeux, conflits et représentations sociales. Thèse de doctorat d'Etat, Université de Provence. Aix-en-Provence, France; 1976.

4. Gaymard S. The theory of conditionality: an illustration of the place of norms in the field of social thinking. Journal for the Theory of Social Behaviour. 2014;44(2):229-247. 
5. Gaymard S. Pedestrian representation through the analysis of little stories. Psychology of Language and Communication. 2012;16(3):185-200.

6. Gaymard S, Maurin M. Rank Ordering of Questionnaire Items Using Wilks' Statistics: An Example of Application to Three Populations. Cross-Cultural Communication. 2017;13(1):1-9.

7. Gaymard S, Tiplica T. Conditionality and risk for the pedestrian: modelling with the Bayesian Networks. Int J Inj Contr Saf Promot. 2015;22(4):340-351.

8. Gaymard S, Lethielleux C. La représentation sociale de la vie de quartier chez des femmes retraitées. Revue Québécoise de Psychologie. 2015;36(3):121-149.

9. Gaymard S. La négociation interculturelle chez les filles francomaghrébines. Une étude de représentation sociale. L'Harmattan, Paris; 2003.
10. Vergès P. L'analyse des représentations sociales par questionnaires. Revue Française de Sociologie. 2001;42(3):537-541.

11. Gaymard S, Bordarie J. The perception of the ideal neighborhood: A preamble to implementation of a "street use code". Social Indicators Research. 2015;120(3):801-816.

12. Hartman RL, Huestis MA. Cannabis Effects on Driving Skills. Clinical Chemistry. 2013;59(3):1-15.

13. Cougle JR, Hakes JK, Macatee RJ, et al. Probability and correlates of dependence among regular users of alcohol, nicotine, cannabis, and cocaine: concurrent and prospective analyses of the National Epidemiologic Survey on Alcohol and Related Conditions. J Clin Psychiatry. 2016;77(4):444-450. 